\title{
Accuracy of prospective memory tests in mild Alzheimer's disease
}

\author{
Acurácia dos testes de memória prospectiva na doença de Alzheimer leve \\ Sergilaine Pereira Martins', Benito Pereira Damasceno²
}

\begin{abstract}
Objectives: To verify the accuracy of prospective memory (ProM) tests in Alzheimer's disease (AD). Methods: Twenty mild AD patients (CDR 1), and 20 controls underwent Digit Span (DS), Trail Making (TM) A and B, visual perception, Rey Auditory-Verbal Learning tests, and Cornell Scale for Depression. AD diagnosis was based on DSM-IV and NINCDS-ADRDA criteria. ProM was assessed with the appointment and belonging subtests of Rivermead Behavioral Memory Test (RBMT); and with two new tests (the clock and animal tests). Results: AD patients had a worse performance than controls on the majority of tests, except DS forward and TM-A. There was no correlation between RBMT and the new ProM tests. As for accuracy, the only significant difference concerned the higher sensitivity of our animal test versus the RBMT belonging test. Conclusions: The clock and the animal tests showed similar specificity, but higher sensitivity than the RBMT subtests.
\end{abstract}

Key words: prospective memory, Alzheimer's disease, neuropsychological tests, dementia, aging.

\section{RESUMO}

Objetivos: Verificar a acurácia dos testes de memória prospectiva (MP) na doença de Alzheimer (DA). Métodos: Foram avaliados 20 pacientes com DA leve (CDR 1; diagnóstico baseado no DSM-IV e NINCDS-ADRDA) e 20 controles passaram pelos testes de dígitos, das trilhas A e B, de percepção visual, do aprendizado verbal de Rey e da Escala Cornell para Depressão. MP foi avaliada com os subtestes de compromisso e pertence do Teste de Memória Comportamental da Rivermead e dois novos testes (do relógio e dos animais). Resultados: Os pacientes com doença de Alzheimer tiveram um desempenho inferior aos controles na maioria dos testes, exceto nos dígitos diretos e na trilha A. Não houve correlação entre os subtestes de Memória Comportamental da Rivermead e os novos testes de memória prospectiva. A única diferença quanto à acurácia foi que o teste dos animais teve maior sensibilidade que o do pertence da Rivermead. Conclusões: Os testes do relógio e dos animais mostraram similar especificidade, porém maior sensibilidade do que os subtestes da Rivermead.

Palavras-Chave: memória prospectiva, doença de Alzheimer, testes neuropsicológicos, demência, envelhecimento.

Alzheimer's disease $(\mathrm{AD})$ is characterized by progressive loss of cognitive functions with impairment of daily life activities of the affected elderly people. Loss of memory is, in general, the first and most important symptom ${ }^{1}$. Impaired ability to learn new information or to recall previously learned information (i.e., retrospective episodic memory) is required for the operational diagnosis of the disease. However, memory is a complex functional system, and other types of memory than the retrospective episodic (e.g., semantic, prospective) may be early impaired in AD.

As conceived of by Tulving ${ }^{2}$, the episodic retrospective memory (RetM) represents events in his personal biographic history. It involves conscious recollection of these episodes ( for example, when one was getting married), and it is typically evaluated by means of learning a list of words or a series of figures.
In the $\mathrm{AD}$, RetM deficit, particularly the free and delayed recall of series of words, sentences, or objects, occurs earlier than the medial temporal atrophy shown by magnetic resonance imaging, and it is considered the most reliable predictor of the disease in its preclinical stage ${ }^{3}$.

Impairment of prospective memory (ProM), though a common initial complaint of $\mathrm{AD}$ patients, has been neglected in cognitive studies of the disease. While RetM is the memory of the past, ProM is the memory of the future ${ }^{4}$. ProM consists in remembering to carry out intended actions at an appropriate point in the future, such as to keep appointments, pay bills, take medicine, carry out domestic chores, and give one person the message that someone else has called.

To perform a ProM task, one must remember there was an intention (the prospective component) and the contents of the

${ }^{1}$ Postgraduate Neurologist, State University of Campinas (UNICAMP), Campinas SP, Brazil;

${ }^{2}$ MD, PhD, Professor, Department of Neurology, Medical School, State University of Campinas (UNICAMP), Campinas SP, Brazil.

Correspondence: Benito Pereira Damasceno; Department of Neurology, Medical School, State University of Campinas; Rua Tessália Vieira de Camargo, 126 Caixa Postal: 6111;13083-970 Campinas SP - Brasil; E-mail: damascen@unicamp.br

Conflict of interest: There is no conflict of interest to declare.

Received 06 December 2010; Received in final form 26 August 2011; Accepted 02 September 2011 
intention, "what to do" (the retrospective component). This retrospective component is highly dependent on the medial temporal lobe structures, it is what makes ProM (to memorize or learn a list of things to do in the future) to be similar to RetM (to remember a list of events from the past), and constitutes one of the reasons why ProM and RetM are usually impaired in the early stages of the $\mathrm{AD}^{5,6}$. The prospective component is what characterizes ProM as unique, different from learning, in that it is the memory of an intention, essential for goal-directed behaviors. As highlighted by Karantzoulis et al. ${ }^{7}$, even such prospective component is a complex process, which involves at least four stages: intention formation, to plan the future activity, i.e., what and when to do it; intention retention, to hold the intention in memory while other activities are occurring, i.e., during the ongoing task; intention initiation, the point at which the appropriate cue (e.g., an event) triggers an effortful and controlled search of memory for the intention; and intention execution, when the retrieval context actually occurs and the action of the intended action is executed.

In tests for assessment of RetM, the recovery of information requires an active and conscious process. This pattern does not apply for ProM. The tests, which have been applied to assess ProM, involve the presentation of information to which the patient will be asked to recognize or recall later on in response to a signal provided by the examiner ${ }^{8}$. Einstein and $\mathrm{McDaniel}^{9}$ classify ProM tasks according to a factor that triggers action: it may be a particular event (ProM based on an event) or a determined time (ProM based on time).

Since until recently the research on memory had tended to neglect ProM, it is not surprising that the traditional memory test batteries ( for example, Wechsler's battery) ${ }^{10}$ do not include tests for assessment of ProM.

One of the first attempts to include ProM tasks in clinical assessment was the Rivermead Behavioral Memory Test battery $(\mathrm{RBMT})^{11}$, which consists of two event-based ProM tasks: the appointment and belonging tests. These tests are event-based and require that the subject remembers to perform a simple action later on during the assessment session.

The aim of this study was to investigate the performance of patients with mild $\mathrm{AD}$ as compared to healthy control subjects on two new ProM tests, which were developed by the authors (the clock test, based on time; and the animal one, based on an event), and to compare the accuracy of these two tests with that of the appointment and the belonging tasks of the RBMT ${ }^{12}$. This study was approved by the Medical School Ethics Committee. All the patients and controls signed the informed consent form.

\section{METHODS}

We studied 20 patients with mild $\mathrm{AD}$ followed-up in the Neuropsychology Unit of the State University of Campinas
(UNICAMP) Hospital, and 20 normal matched controls. Routine laboratory examinations for dementia assessment (including B12 and folic acid dosage, serology for syphilis, thyroid hormones) and brain computed tomography were carried out in all patients.

The diagnosis of probable AD was based on DSM-IV ${ }^{1}$ and NINCDS-ADRDA criteria ${ }^{13}$, and its severity, on the Clinical Dementia Rating $(\mathrm{CDR})^{14}$. We included only patients with Mini-Mental State Examination (MMSE) ${ }^{15}$ scores between 16 and 24, and CDR score of 1. Exclusion criteria were: history of other neurological or psychiatric diseases, drug or alcohol addiction, and prior exposition to neurotoxic substances. Control subjects were matched to the patients for age $( \pm 5$ years) and education ( \pm 2 years), with CDR 0 , and without previous history of neurological or psychiatric disease, or memory complaints. A detailed interview and a battery of neuropsychological tests were applied to all of them.

The neuropsychological assessment comprised the following tests, for which all subjects repeated the instruction for the proposed tasks in order to verify their understanding.

The ProM was assessed using two tests of the RBMT (Brazilian version validated by Yassuda et al., 2010) ${ }^{12}$ : the appointment and the belonging test; and two other tests developed by the authors: the clock and the animal ones.

\section{Appointment test}

The subjects are required to ask for their next appointment when they hear the ringing of the alarm clock, which is set to go off 15 minutes after the instruction has been given. Scoring system: one point if the correct response was given following a prompt ("What were you going to do when the alarm rang?") and two if it was given without a prompt (maximum score=2).

\section{Belonging test}

At the beginning of the session, the examiner borrows from the subject a personal belonging, which the examiner hides, letting the subject know where it is hidden (e.g., into a drawer) with an instruction that the subject asks for it to be returned at the end of the session. Then, at the end of the session, the examiner says: "That is the end of the session". If the subject does not spontaneously request the belonging, the examiner gives a prompt: "Was there something you were going to ask me for?" Scoring: one point if the subject recalled the item, another one if he/she recalled the location and additional points for each response which was given without a prompt (maximum score $=4$ ).

\section{Animal test}

Subjects are told that they are going to see 20 photographs of animals, one at a time (during five seconds), and that his/her task is to name each animal (naming task) and, in case he/she sees some object or food in the mouth of the animal, 
to inform to the examiner (this is a ProM task embedded in a naming task). For the ProM task, there are two photographs: one in the $5^{\text {th }}$ and another in the $19^{\text {th }}$ position. Scoring: one point for each correct response (maximum score=2).

\section{Clock test}

At the beginning of the session, the subject is asked to remind the examiner of an appointment five minutes afterwards, with the instruction: "In five minutes I have to tell to the nurse about a medication. Could you please remind me to go to talk to her on five minutes?" This time is spent with other tests or activities. There must be a clock visible in the periphery of the subject visual field. Scoring: two points if the subject reminds the examiner after five minutes with an error of ( \pm ) 30 seconds; one for errors higher than this (and none if there is no reminding); (maximum score $=2$ ).

As regards to the last two ProM tests (the animal and the clock ones), they were developed by the authors in an experimental attempt to improve the accuracy of ProM tests, so they have no previous psychometric validation. Their construction followed the criteria proposed by McDaniel and Einstein ${ }^{16}$ for creating typically prospective tasks:

- the execution of the intended action must not be immediate: not be executed immediately after the intention, but delayed or postponed to some point in the future;

- the ProM task must be embedded in another ongoing activity;

- the time frame for response must be limited: to have constrained time frame of opportunities in which forgetting or recalling of the task is required for initiating the intended action;

- to have limited time frame for accomplishing the action, it cannot be a task that requires long time to be carried out (e.g., reading a book or going on a trip) and in case of tasks in laboratory, it must be carried out in seconds or in a few minutes;

- there must be an intention - this is a critical factor that characterizes the ProM task: to be based on an consciously formed intention or plan; and

- the formed intention should not be maintained in working memory, in the focus of consciousness, but temporarily forgotten by performing other activities, otherwise it would constitute a vigilance task, not a ProM one.

The subjects have also been tested for other cognitive functions whose deficits could interfere with the performance of ProM tasks (counterproofs): attention/concentration - digit span subtest of WMS- $\mathrm{R}^{10}$; executive function - trail making $\mathrm{A}$ and $\mathrm{B}^{17}$; depression and anxiety - Cornell Scale for Depression in Dementia (CSDD) ${ }^{18}$; visual perception - abstract figures (modified from Jones-Gotman et al. ${ }^{19}$; and RetM - Rey Auditory-Verbal Learning Test (RAVLT) ${ }^{17}$.
The statistical analysis was carried out using SAS System for Windows ${ }^{20}$, version 9.1.3. We used Student's $t$-test to compare patients and controls as for age and education; and Wilcoxon signed rank test for matched pairs to compare their performance on the neuropsychological tests. McNemar's exact test was used to compare the ProM subtests with each other as regards the performance of $\mathrm{AD}$ patients on these tests. We also used the average weighted Kappa coefficient for correlation and measurements of accuracy, assessing the sensitivity and specificity for each of the ProM tests. Statistical significance considered was $\mathrm{p}<0.05$.

\section{RESULTS}

There were 9 men and 11 women in each group. Dementia

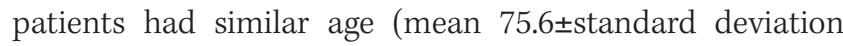
7.8 versus $73.8 \pm 6.5$ years; $\mathrm{p}=0.447)$ and educational level as controls ( $5.6 \pm 4.5$ versus $5.8 \pm 4.4$ years; $p=0.915)$. They also performed as controls on digit span forward $(p=0.324)$ and trail making A ( $\mathrm{p}=1.000)$, but worse on MMSE (22.6 \pm 1.9 versus 29.0 $\pm 1.3 ; \mathrm{p}=0.0001$ ), digit span backwards (3.3 \pm 0.7 versus $4.0 \pm 0.9 ; \mathrm{p}=0.0005)$, trail making $\mathrm{B}(12.3 \pm 5.7$ versus $21.0 \pm 6.0$; $\mathrm{p}=0.0001)$, visual perception $(8.1 \pm 1.3$ versus $9.0 \pm 0.9 ; \mathrm{p}=0.015)$, RAVLT delayed recall $(1.1 \pm 1.6$ versus $6.65 \pm 2.6 ; \mathrm{p}<0.0001)$. Dementia patients ProM total scores were inferior to those of controls ( $4.1 \pm 2.5$ versus $8.8 \pm 1.2 ; \mathrm{p}<0.0001$ ). Their performance was particularly worst on the clock $(p=0.0004)$, the belonginglocation $(\mathrm{p}=0.0003)$, the animals $(\mathrm{p}<0.0001)$, and the appointment $(p<0.0001)$ subtests. Only two ProM tests were correlated with RAVLT mean score of five immediate recall trials: the animals $(\mathrm{r}=5372, \mathrm{p}<0.05)$ and the appointment $(\mathrm{r}=4706$, $\mathrm{p}<0.05$ ), but without significant correlation with RAVLT delayed recall ( $\mathrm{r}=0.3288$ and $\mathrm{r}=0.2233$, respectively). Cornell Scale for Depression in Dementia (CSDD) showed no signs of depression in the Dementia Group. In this scale, nine dementia patients scored 0 , and 11 scored 1 or 2 . In the dementia subgroup with scores 1 (eight subjects) or 2 (three subjects), the analysis of correlation between CSDD and ProM scores showed a statistically significant relationship only with the animals' test ( $r=0.606, p<0.05$, two-tailed), but this correlation was positive, which means that CSDD scores did not influence negatively the performance on ProM tasks.

In order to compare the performance of the groups on the ProM tests of the RBMT with the clock and animal tests, the correlation between the memory subtests was measured using the average weighted Kappa coefficient. For the interpretation of the magnitude of this coefficient, values $\geq 0.75$ indicate excellent correlation, values between 0.75 and 0.40 point to good correlation and values $\leq 0.40$ indicate no correlation. All our values were below 0.40 , thus indicating no correlation between RBMT and our tests, and suggesting they are not equivalent (Table 1). 
The performance of the groups on RBMT ProM tests (appointment, belonging-item and belonging-location tests) and on the clock and the animal tests was analyzed by assessing their accuracy (sensitivity and specificity), as seen in Table 2. Statistical analysis with the Cochran test showed significant difference for sensitivity only in the comparison of the belonging-item test versus the animal one $(\mathrm{p}=0.0469)$. No significant difference was found for specificity.

\section{DISCUSSION}

All subjects could understand what was expected of them in the tasks proposed. Even those who failed in ProM tests could, at the end of the testing session, remember the instructions that had been given to them.

$\mathrm{AD}$ patients showed significantly inferior performance on all ProM tasks: animals, appointment, clock, and belonginglocation tests. This inferior performance cannot be related to age, for the small difference of age between the two groups was not statistically significant. Furthermore, the age effect on cognitive performance is usually secondary to the effect of education level ${ }^{15,21}$, which was similar in both groups. The difficulties experienced by $\mathrm{AD}$ patients can neither be explained by deficit of attention, visual perception or executive function, for there was not a correlation between ProM and the control tests for these cognitive functions.

The impairment of ProM in the present patients was expected, since $\mathrm{AD}$ affects multiple cognitive domains, first and foremost memory, and its different subtypes ${ }^{22}$. We found that only two ProM tests (the animals and the appointment) were correlated to RAVLT immediate recall, but not with RAVLT delayed one. This finding indicates that the ProM tests are related to intention formation and working memory operations involved in the immediate recall of the word list, but not to the specifically RetM component required for delayed recall. Thus, these ProM tests do not evaluate the same memory component (retrospective, episodic) assessed by RAVLT.

Moreover, other studies ${ }^{5,6,23-25}$ have shown that ProM is primarily and early affected in $\mathrm{AD}$, independently of the concurrent deficit of RetM. There are indications that ProM and RetM depend on different cognitive processes and different brain regions. Performance on ProM tests is more reliant on intention formation, strategic planning, self-initiated retrieval, and interruption or inhibition of ongoing actions, which are cognitive processes highly dependent on the frontal lobes, but not on the hippocampal system. Positron emission tomography (PET) studies of young adults performing ProM tasks have found several localized brain activations, particularly in the right dorsolateral and ventrolateral prefrontal cortices, anterior cingulate gyrus, left parahippocampal gyrus, and midline medial frontal lobe ${ }^{5}$. The authors of this article related these localized activations to specific cognitive operations involved in ProM, such as: holding an intention toward future behavior, checking target items within presented stimuli, and dividing attention between the planned ProM action and the routine activity in which it was embedded.

Contrary to our expectations, we found no correlation between the RBMT and our ProM (the animals and the clock tests), indicating that they do not evaluate ProM in the same

Table 1. Correlation between the prospective memory tests (Kappa index coefficients).

\begin{tabular}{lccc} 
Test & Belonging test - item & Belonging test - location & Appointment test \\
\hline \multirow{2}{*}{ Animal } & AD 0.1707 & AD 0.1626 & AD 0.3617 \\
& CO -0.1538 & CO 0.1475 & CO -0.1905 \\
Clock & AD -0.0837 & AD 0.1045 & AD 0.1139 \\
& CO -0.2857 & CO 0.1667 & CO 0.1111 \\
\hline
\end{tabular}

AD: Alzheimer's disease Group; CO: Control Group.

Table 2. Accuracy of ProM tests for diagnosis of Alzheimer's disease.

\begin{tabular}{|c|c|c|c|c|c|}
\hline \multirow{2}{*}{ ProM tests } & & \multirow{2}{*}{$A D$} & \multirow{2}{*}{$\mathrm{CO}$} & \multicolumn{2}{|c|}{ Accuracy } \\
\hline & & & & Sensitivity (\%) & Specificity (\%) \\
\hline \multirow[t]{2}{*}{ Clock test } & Impaired & 15 & 5 & 75 & 75 \\
\hline & Normal & 5 & 15 & & \\
\hline \multirow[t]{2}{*}{ Appointment test } & Impaired & 18 & 3 & 90 & 85 \\
\hline & Normal & 12 & 17 & & \\
\hline \multirow[t]{2}{*}{ Belonging test - item } & Impaired & 11 & 7 & 55 & 65 \\
\hline & Normal & 9 & 13 & & \\
\hline \multirow[t]{2}{*}{ Belonging test - location } & Impaired & 13 & 2 & 65 & 90 \\
\hline & Normal & 7 & 18 & & \\
\hline \multirow[t]{2}{*}{ Animal test } & Impaired & 17 & 5 & 85 & 75 \\
\hline & Normal & 3 & 15 & & \\
\hline
\end{tabular}

ProM: prospective memory; AD: Alzheimer's disease Group; CO: Control Group. 
way. Thus, we cannot conclude whether any of them is more suitable for studying this subtype of memory. On the other hand, we also evaluated the accuracy of these tests in distinguishing $\mathrm{AD}$ from normal aging by comparing the patients' sensitivity and specificity. All four ProM tests showed similar accuracy, except that the animals' test was more sensitive than the belonging-item one.

Although several authors have found that ProM is early affected in $\mathrm{AD}$, few studies have yielded effective tests for assessing this type of memory. The guidelines proposed by McDaniel and Einstein ${ }^{16}$ for creating informative ProM tasks have contributed to the elaboration of new instruments to assess a more comprehensive cognitive profile of $\mathrm{AD}$, already in the initial stages of the disease.

This study presents some limitations. The sample is small and the scoring system has a limited variation of scores (0, 1 and 2); thus, rendering difficult the statistical analysis. In spite of these limitations, we can conclude that the clock and the animals' tests - used for the first time in this study - have similar or even higher sensitivity than the ProM tests of RBMT battery; there were no differences in performance between the ProM tests based on time and those based on event; and both ProM and RetM are significantly impaired in the mild phase of $\mathrm{AD}$.

\section{References}

1. American Psychiatric Association. Diagnosis and statistical manual of mental disorders (4th ed.): text revised. Washington, DC: APA; 1994.

2. Tulving E. Multiple memory systems and consciousness. Human Neurobiol 1987;6:67-80.

3. Dubois B. Prodromal Alzheimer's disease: a more useful concept than mild cognitive impairment? Curr Op Neurol 2000;13:367-369.

4. Ingvar DH. Memory of the future:an essay on the temporal organization of conscious awareness. Human Neurobiol 1985;4:127-136.

5. Jones S, Livner A, Bäckman L. Patterns of prospective and retrospective memory impairment in preclinical Alzheimer's disease. Neuropsychology 2006;20:144-152.

6. Martins SP, Damasceno BP. Prospective and retrospective memory in mild Alzheimer's disease. Arq Neuropsiquiatr 2008;66:318-322.

7. Karantzoulis S, Troyer AK, Rich JB. Prospective memory in amnestic mild cognitive impairment. J Internat Neuropsychol Soc 2009; 15:407-415.

8. Einstein GO, McDaniel MA, Richardson SL, Guynn MJ. Aging and prospective memory: Examining the influences of self-initiation retrieval processes. Learning, memory, and cognition. J Exp Psychol 1995;21:996-1007.

9. Einstein GO, McDaniel MA. Normal aging and prospective memory. Learning, memory, and cognition. J Exp Psychol 1990;16:717-726.

10. Wechsler D. Wechsler Memory Scale. San Antonio, TX: The Psychological Corporation; 1997.

11. Wilson BA. The development and validation of a test of everyday memory behavior. J Clin Exp Psychol 1989;11:855-887.

12. Yassuda MS, Flaks MK, Viola LF, et al. Psychometric characteristics of the Rivermead Behavioral Memory Test (RBMT) as an early detection instrument for dementia and mild cognitive impairment in Brazil. Internat Psychogeriatrics 2010;22:1003-1011.

13. McKhann G, Drachman D, Folstein M, Katzman R, Price DL, Stadlan EM. Clinical diagnosis of Alzheimer's disease: report of the NINCDSADRDA Work Group under the auspices of Department of Health and Human Services Task Force on Alzheimer's disease. Neurology 1984;34:939-944.

14. Morris JC. The clinical dementia rating (CDR): current version and scoring rules. Neurology 1993;43:2412-2414.

15. Brucki SMD, Nitrini R, Caramelli P, Bertolucci PHF, Okamoto IH. Sugestões para o uso do mini-exame do estado mental no Brasil. Arq Neuropsiquiatr 2003;61:777-781.

16. McDaniel MA, Einstein GO. Prospective memory: an overview and synthesis of an emerging field. Los Angeles, CA: Sage Publications; 2007.

17. Spreen O, Strauss E. A compendium of neuropsychological tests: administration, norms, and commentary. Oxford: Oxford University Press; 1998

18. Alexopoulos GS, Abrams RC, Youn RC, Shamoian CA. Cornell Scale for depression in dementia. Biol Psychiatry 1988;23:271-284.

19. Jones-Gotman M, Zatorre RJ, Olivier A, et al. Learning and retention of words and designs following excision from medial or lateral temporallobe structures. Neuropsychology 1997;35:963-973.

20. SAS System for Windows (Statistical Analysis System), version 9.1.3. Cary, NC: SAS Institute, Inc; 2002-2003.

21. Porto CS, Fichman HC, Caramelli P, Bahia VS, Nitrini R. Brazilian version of the Mattis Dementia Rating Scale: diagnosis of mild dementia in Alzheimer's disease. Arq Neuropsiquiatr 2003;61:339-345.

22. Small SA, Stern Y, Tang M, Maueux R. Selective decline in memory function among healthy elderly. Neurology 1999;52:1392-1396.

23. Huppert FA, Beardsall L. Prospective memory impairment as an early indicator of dementia. J Clin Exp Neuropsychol 1993;15:805-821.

24. Maylor EA, Smith G, Sala SD, Logie RH. Prospective and retrospective memory in normal ageing and dementia: A questionnaire study. Memory 2000;8:311-321.

25. Duchek JM, Balota DA, Cortese M. Prospective memory and apolipotrotein $\mathrm{E}$ in healthy aging and early stage Alzheimer's disease. Neuropsychology 2006;20:633-644. 